\title{
Long term angiographic and clinical follow up in patients with stent implantation for symptomatic myocardial bridging
}

\author{
P K Haager, E R Schwarz, J vom Dahl, H G Klues, T Reffelmann, P Hanrath
}

\begin{abstract}
Objective-To assess long term results of coronary stent implantation in patients with symptomatic myocardial bridging.

Methods-Intracoronary stent implantation was performed within the intramural course of the left anterior descending coronary artery in 11 patients with objective signs of myocardial ischaemia and absence of other cardiac disorders. All had myocardial bridging of the central portion of the left anterior descending coronary artery. Quantitative coronary angiography was performed before and after stent deployment, and again at seven weeks and six months. Clinical evaluation was done at two years.

Results-After stent deployment, quantitative coronary angiography showed absence of systolic compression along the left anterior descending coronary artery; the minimum luminal diameter (mean (SD)) increased from $0.6(0.3) \mathrm{mm}$ before stent implantation to $1.9(0.3) \mathrm{mm}$ after implantation $(\mathrm{p}<0.05)$. Intravascular ultrasound showed an increase in cross sectional area from $3.3(1.3) \mathrm{mm}^{2}$ at baseline to $6.8(0.9) \mathrm{mm}^{2}(\mathrm{p}<0.005)$ after stent deployment. Coronary flow reserve was normalised from $2.6(0.5)$ at baseline to $4.0(0.5)(\mathrm{p}<0.005)$ after stent implantation. At seven weeks, quantitative coronary angiography showed mild to moderate or severe in-stent stenosis in five of the 11 patients; four of these underwent repeat target vessel revascularisation (percutaneous transluminal coronary angioplasty in two; coronary artery bypass grafting in two). At six months, all patients $(n=9)$ showed good angiographic results, including those who had target vessel revascularisation. On clinical evaluation at two years, all patients (including those with target vessel revascularisation) remained free of angina and cardiac events. Conclusions-Intracoronary stent implantation prevents external compression of bridged coronary artery segments, with increase in luminal diameter and alleviation of symptoms. The incidence of in-stent stenosis requiring target vessel revascularisation (36\%) is comparable with that of lesions of $25 \mathrm{~mm}$ length in coronary artery disease. The symptom free and event free two year follow up data suggest that stent implantation is a useful way of treating symptomatic patients with myocardial bridges.
\end{abstract}

(Heart 2000;84:403-408)

Keywords: myocardial bridging; stent; restenosis

Myocardial bridges are the most common inborn coronary anomalies, ${ }^{1}$ with an incidence between $1.5 \%$ and $16 \%$ as assessed by coronary angiography, ${ }^{2}$ and up to $80 \%$ as assessed at necropsy. ${ }^{3}$ Though in most cases this is considered a harmless vessel malformation, ${ }^{4}$ the intramural course of certain portions - mainly in the left anterior descending coronary artery-may cause myocardial ischaemia. Clinically relevant complications may occur, such as anginal symptoms requiring anti-ischaemic treatment, arrhythmias, and even myocardial infarction. ${ }^{5-11}$ Standard treatment involves $\beta$ adrenergic receptor blockers, ${ }^{12}{ }^{13}$ surgery with dissection of the overlying muscle fibres, or coronary artery bypass grafting. ${ }^{14}{ }^{15}$ Intracoronary stent implantation has been attempted as an alternative treatment in individual patients with myocardial bridging. ${ }^{16-20}$ However, there are few reports confirming that intracoronary stent implantation results in relief of mural vessel compression and thus alleviation of the underlying haemodynamic alterations that lead to myocardial ischaemia. ${ }^{21-23}$ No systematic long term follow up of a group of patients with stent implantation within bridged coronary segments has yet been reported.
Our aim in the present study was to assess the clinical, angiographic, and functional follow up over time after stent implantation in patients with symptomatic myocardial bridging.

\section{Methods}

PATIENT SELECTION

The study population consisted of 11 consecutive and otherwise healthy patients. Demographic and clinical data on the patients are given in table 1 . All patients had had at least one previous hospital admission because of symptoms of angina, and six had a history of previous non-transmural myocardial infarction. Exercise stress testing using bicycle ergometry showed significant ST segment depression of $>0.2 \mathrm{mV}$ or terminal $\mathrm{T}$ wave inversion in the anterior leads during or after exercise in four of the 11 patients, while six had a positive Tc-99m sestamibi SPECT (single photon emission computed tomography) test (55\%) with filling defects during stress which were reversible at rest; the remaining patient had reproducible angina during stress testing.

No evidence of coronary atherosclerosis was found on coronary angiography. Myocardial 
Table 1 Demographic and clinical characteristics in 11 patients with myocardial bridging and stent implantation

\begin{tabular}{ll}
\hline Age (years) (mean (SD)) & $52(12)$ \\
Sex (male/female) & $10 / 1$ \\
Angina pectoris (n) & 11 \\
$\quad$ Typical & 6 \\
Atypical & 5 \\
CCS class (n) & \\
II & 2 \\
III & 9 \\
IV & - \\
No of previous hospital admissions* (mean & $2.5(1.0)$ \\
$\quad$ SD)) & 6 \\
Patients with previous myocardial infarction & \\
$\quad$ (non-transmural) (n) & 11 \\
Positive stress test (n) & 11 \\
$\quad$ Ergometry (total) & 4 \\
$\quad$ Positive & 7 \\
$\quad$ Tc-99m sestamibi (total) & 6 \\
$\quad$ Positive & 2 \\
History of severe arrhythmia† & 9 \\
Hypertension & 8 \\
Smoking & 9 \\
Cholesterol raised & 1 \\
Diabetes mellitus & 4 \\
Family history of coronary artery disease &
\end{tabular}

^Because of anginal symptoms; tventricular fibrillation and/or tachycardia. CCS, Canadian Cardiovascular Society.

bridging of the central portion of the left anterior descending coronary artery was identified in all the patients.

The study protocol was approved by the ethics committee of the RWTH University Hospital, and written informed consent was obtained. The short term results of the first three patients were the subject of a previous report. ${ }^{21}$

\section{CORONARY ANGIOGRAPHY AND QUANTITATIVE}

DIAMETER MEASUREMENTS

Cardiac catheterisation was performed as previously described. ${ }^{1321}$ Quantitative diameter measurements of the coronary arteries were obtained from monoplane digital images on a workstation with dedicated software (CAAS II; Pye Medical, Maastricht, Netherlands). The following variables were assessed:

- per cent diameter stenosis at the most severe site of the myocardial bridge - that is, the portion with the maximum external compression (during systole and mid-diastole);

- the reference diameter of the adjacent proximal and distal epicardial segments;

- the minimum absolute lumen diameter;

- the total length of the bridged coronary artery segment.

An assessment of interobserver and intraobserver variability in the quantitative angiographic measurements was made as previously described and the results correlated well with the published data. ${ }^{21}{ }^{24}$ Correlation coefficients and standard errors of the estimate (SEE) for absolute systolic and diastolic lumen diameter for interobserver (and intraobserver) variability were $r=0.91$, SEE $0.06 \mathrm{~mm}(r=0.95$, SEE $0.05 \mathrm{~mm}$ ) and for per cent lumen reduction, $r=0.92$, SEE $4 \%(r=0.98, \operatorname{SEE} 2 \%)$.

\section{INTRACORONARY FLOW VELOCITY}

MEASUREMENTS

Intracoronary Doppler flow profiles were obtained using a 0.014 inch $(0.36 \mathrm{~mm})$ flexible Doppler guide wire (FloWire, Cardiometrics Inc, Mountain View, California, USA). ${ }^{13} 24-27$ Flow velocities were measured proximal to the bridged segments, distal to the bridged segments, and within the bridged segments during several careful pull back manoeuvres before and after stent implantation and at seven weeks follow up, as previously described. ${ }^{21}$ Coronary flow reserve was determined after intracoronary injection of $12 \mathrm{mg}$ papaverine, locating the transducer distal to the bridged coronary segments. ${ }^{2128}$

\section{STENT IMPLANTATION AND INTRAVASCULAR} ULTRASOUND

We assumed that the optimal stent design for treatment of myocardial bridging would be a highly flexible modified slotted tube stent or a modular stent providing optimum flow through severely angulated segments and allowing exact stent placement within the myocardial bridge. Good radial strength also seemed necessary to provide a firm scaffold under the myocardial bridge. ${ }^{29} 30$

For the first three patients we used standard biaxial techniques; for the remaining eight patients monorail techniques were applied for stent delivery. In all, 18 stents were used (16 Multilink, Guidant, Hampshire, UK, in 10 patients; two NIR stents, Boston Scientific Corporation, Maple Grove, Minnesota, USA, in one patient). These had a mean (SD) length of 30 (11) $\mathrm{mm}$ and an average (nominal) stent diameter of $3.0 \mathrm{~mm}$. Calculated balloon to artery ratio was 1.3 to 1.6 . Oversizing was intentionally performed by the investigators to achieve maximum luminal gain. Inflation pressures of 8-12 atm were used during primary implantation. Suboptimal stent expansion was identified during intravascular ultrasound examination using a 3.5 French 20 or $32 \mathrm{MHz}$ monorail mechanical intravascular ultrasound catheter, connected to an ultrasound console (Boston Scientific Corporation, Sunnyvale, California); in such cases, high pressure inflation ( $>14 \mathrm{~atm}$ ) was performed using a compliant balloon. Optimal stent expansion was based on previously described criteria. ${ }^{31}$

In six patients, optimal visualisation of the true length of the myocardial bridge was inadequate at baseline angiography, so provocative manoeuvres were performed. In two of these patients, intracoronary injection of glyceryl trinitrate $(0.2 \mathrm{mg})$ allowed delineation of the myocardial bridge ${ }^{32}$; in four, dobutamine infusion resulted in increased systolic lumen reduction (starting with $10 \mu \mathrm{g} / \mathrm{kg}$ body weight/ min and increasing by $10 \mu \mathrm{g}$ every three minutes). At each dose, angiograms were performed until there was no further increase in the length of the myocardial bridge or in the severity of maximum systolic compression. ${ }^{32}$

All patients received $250 \mathrm{mg}$ ticlopidine twice daily, starting the day before stent implantation for a period of two months, in combination with $100 \mathrm{mg}$ aspirin. ${ }^{33}$ All were re-evaluated after seven weeks (angiography with intravascular ultrasound and Doppler flow studies) and after six months (angiography). This relatively short time interval was chosen in order to detect early mechanical stent recoil because of external compression within the stented bridged coronary segments. 


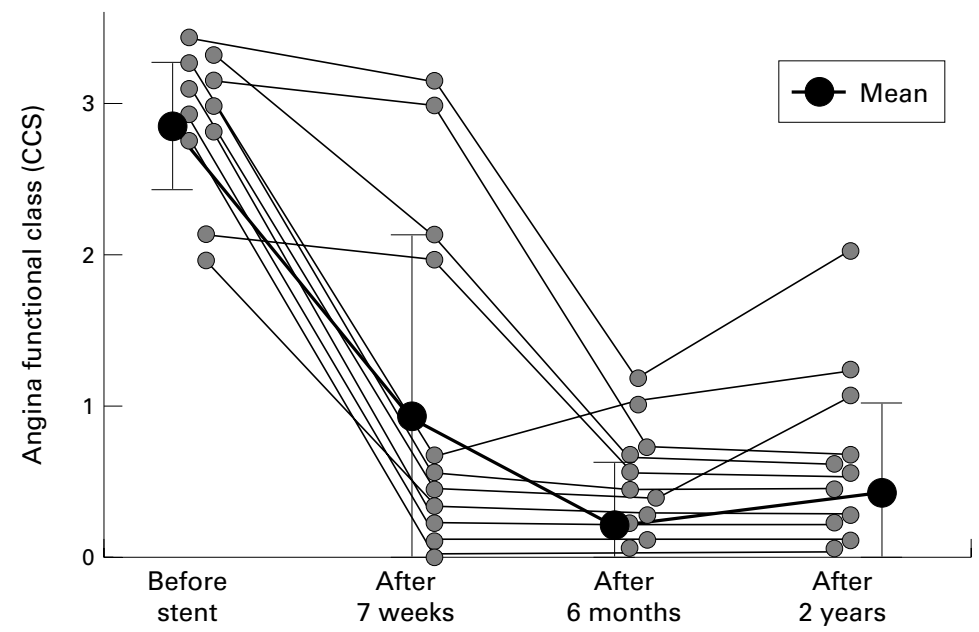

Figure 1 Angina CCS functional class before stent implantation, and after seven weeks, six months, and two years follow up.

Additional angiographic studies were performed in patients with repeated interventional approaches for treatment of restenosis.

FOLLOW UP EXAMINATIONS

At two years after stent implantation, a standardised questionnaire was administered, either by phone or at an outpatient clinic visit, to assess clinical symptoms, daily activities without chest pain or anginal symptoms, subjective symptom quality, objective Canadian Cardiovascular Society (CCS) class status, any hospital admittances or physician visits for chest pain, and current drug treatment.

STATISTICAL ANALYSIS

All values are given as mean (SD). Doppler flow data and pressure values proximal to, within, and distal to the myocardial bridges were compared by analysis of variance for repeated measurements (ANOVA). A probability value of $\mathrm{p}<0.05$ was considered significant.

\section{Results}

CLINICAL FOLLOW UP

The acute clinical success rate was $100 \%$ with respect to the absence of myocardial infarction, death, or other peri-interventional or inhospital complications (rise in creatine kinase, need for bypass surgery). There was no clinical evidence of subacute stent thrombosis. Figure 1 shows changes in the CCS angina class score from baseline to post-stent implantation and during long term follow up (two years). All patients reported an improvement in symptoms shortly after stent implantation. However, four had a recurrence of angina before the seven week angiography. None of the patients who were asymptomatic at seven weeks developed angina of class 2 or more during later follow up.

Four of the symptomatic patients underwent target vessel revascularisation: two had bypass surgery (isolated internal mammary artery to left anterior descending coronary artery), and two had repeated percutaneous coronary angioplasty (PTCA); one of these had additional stent implantation proximal to the previously stented segment. All patients with target vessel revascularisation remained asymptomatic up to the two year follow up. The two patients with repeated PTCA underwent additional angiography after six months, with good long term results (no diameter restenosis of $>50 \%$ ).

None of the patients had myocardial infarction or died during the long term follow up. No patient was admitted to hospital because of angina or other heart related symptoms. Two patients reported symptoms of CCS class 1 or 2; none was classified as CCS class 3 or 4 . At the two year follow up, all patients reported improvement in physical exercise capacity and symptom status when compared with their classification before stent implantation. None of the patients was on chronic treatment with anti-ischaemic drugs, such as nitrates or calcium antagonists.

QUANTITATIVE ANGIOGRAPHIC MEASUREMENTS The quantitative angiography measurements are given in table 2. Maximum systolic diameter reduction before stent implantation was $74(12) \%$ (55-89\%). In addition, there was a persistent diastolic diameter reduction of 34 (10)\% (22-58\%). The length of the myocardial bridge was $25(2) \mathrm{mm}(13-36 \mathrm{~mm})$. Immediately after stent implantation persistent systolic diameter reduction was $12(18) \%(\mathrm{p}<0.005)$, after seven weeks it was $39(18) \%(\mathrm{p}<0.01)$,

Table 2 Quantitative coronary angiography (QCA), intracoronary Doppler flow profiles, and ultrasound measurements

\begin{tabular}{|c|c|c|c|c|}
\hline \multirow[b]{2}{*}{$Q C A(\mathrm{~mm})$} & \multirow[b]{2}{*}{ Baseline } & \multirow{2}{*}{$\begin{array}{l}\text { After stent } \\
\text { implantation }\end{array}$} & \multicolumn{2}{|l|}{ Follow up } \\
\hline & & & 7 weeks & 6 months \\
\hline Reference diameter proximal & $2.3(0.5)$ & $2.3(0.5)$ & $2.3(0.5)$ & $2.3(0.5)$ \\
\hline Reference diameter distal & $1.8(0.4)$ & $1.8(0.4)$ & $1.8(0.4)$ & $1.8(0.4)$ \\
\hline MLD $\$$ (systolic) within MB & $0.6(0.3)$ & $1.9(0.3)^{\star \star}$ & $1.4(0.5)^{\star}$ & $1.3(0.3)^{\star}$ \\
\hline$\%$ systolic diameter reduction & $74(12)$ & $12(18)^{\star \star}$ & $39(18)^{\star}$ & $43(8)^{\star}$ \\
\hline MLD $\$$ (mid-diastolic) within MB & $1.4(0.4)$ & $1.9(0.2)^{\star}$ & $1.4(0.5)$ & $1.4(0.3)$ \\
\hline$\%$ mid-diastolic diameter reduction & $34(10)$ & $15(16)^{\star}$ & $33(15)$ & $41(6)$ \\
\hline \multicolumn{5}{|l|}{ Doppler within myocardial bridge } \\
\hline $\operatorname{APV}(\mathrm{cm} / \mathrm{s})$ & $35(4)$ & $19(4)^{\star}$ & $19(5)$ & NA \\
\hline CFR (distal) & $2.6(0.5)$ & $4.0(0.5)^{\star \star}$ & $3.9(0.9)^{\star \star}$ & NA \\
\hline \multicolumn{5}{|l|}{ IVUS } \\
\hline CSA proximal $(\mathrm{mm})$ & $8.0(0.9)$ & $8.0(0.8)$ & $8.5(0.3)$ & NA \\
\hline CSA (systolic) within $\mathrm{MB}(\mathrm{mm})$ & $3.3(1.3)$ & $6.8(0.9)$ & $5.2(2.2)$ & NA \\
\hline
\end{tabular}

§Including patients with target vessel revascularisation after 7 weeks.

${ }^{\star} \mathrm{p}<0.01,{ }^{\star \star} \mathrm{p}<0.005 v$ baseline.

APV, average peak velocity; CFR, coronary flow reserve; CSA, cross sectional area; IVUS, intravascular ultrasound; MB, myocardial bridge; MLD, minimum luminal diameter; NA, not applicable. 


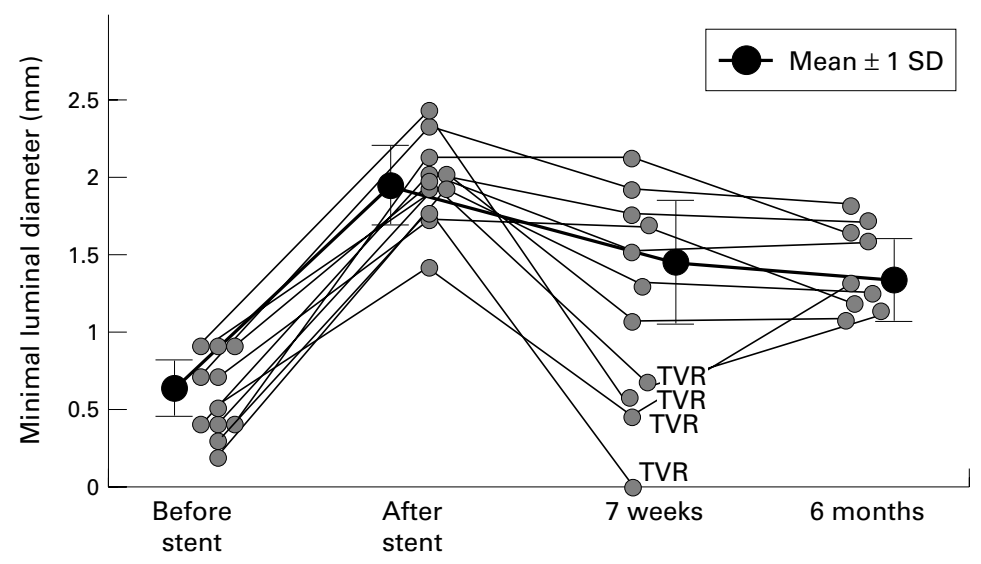

Figure 2 Individual and mean systolic minimal lumen diameter assessed by quantitative coronary angiography before stent implantation, after stent implantation, and at seven weeks and six months follow up. TVR, target vessel revascularisation.

and after six months it was $43(8) \%(\mathrm{p}<0.01$ $v$ systolic diameter reduction immediately after stent implantation; NS $v$ systolic diameter reduction at seven weeks).

Figure 2 shows the individual changes in minimum lumen diameter from baseline to postimplantation and during follow up. By angiographic criteria, five of the 11 patients had intimal proliferation with in-stent stenosis of $\geqslant 50 \%$ at the seven week follow up, including one patient with a total left anterior descending coronary artery occlusion without myocardial infarction. There was no further deterioration in luminal diameters beyond seven weeks, as assessed at the six month angiographic follow up.

INTRACORONARY DOPPLER FLOW VELOCITY MEASUREMENTS AND CORONARY FLOW RESERVE Table 2 shows the results of Doppler flow velocity measurements. The average peak flow
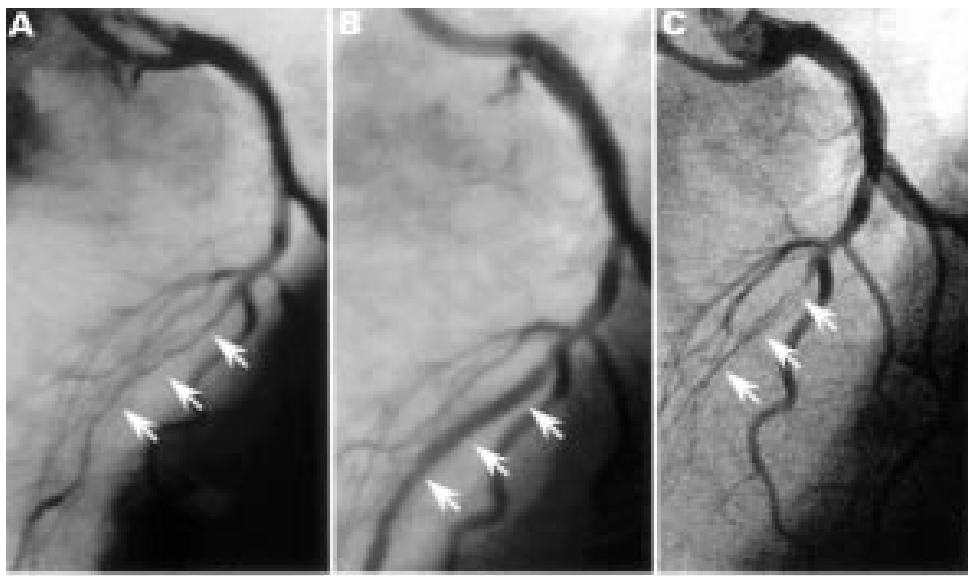

INTRAVASCULAR ULTRASOUND

Measurements of cross sectional area proximal to, distal to, and within the stented coronary segments are given in table 2. Six of the 11 patients showed suboptimal stent expansion after the primary inflation with 10-12 atm and underwent high pressure PTCA (>12 atm) with optimal results during intravascular ultrasound examination. Stent diameters were stable in 10 of the 11 patients, without signs of mechanical recoil, excessive neointimal prolif-
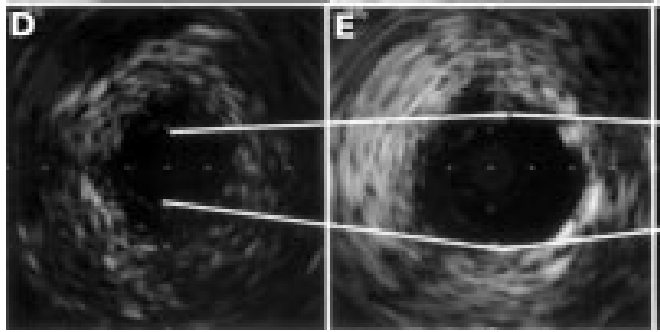

velocity $(\mathrm{cm} / \mathrm{s})$ was significantly greater within the myocardial bridges compared with the and distal coronary segments, and plantation in all patients. Mean coronary flow reserve, obtained distal to the myocardial bridge, was $2.5(0.5)$ before intervention and to $4.0(0.5)$ immediately after stent had a ratio of $>3.0$ before stent delivery. At seven weeks, the patients without in-stent stenosis showed a persistently high coronary repeat before the reintervention (2.0 and 1.7), which was normalised after the second PTCA (to 3.5 and 4.0, respectively). Qualitative analysis of brides flow profiles within the myocardial abrupt early diastolic flow acceleration (finger tip phenomenon), a rapid mid-diastolic deceleration, and a mid to late diastolic plateau, as ary flow during systole was detected proximal to the site of maximum lumen reduction within the bridged segments. All the above flow abnormalities were normalised following stent implantation.
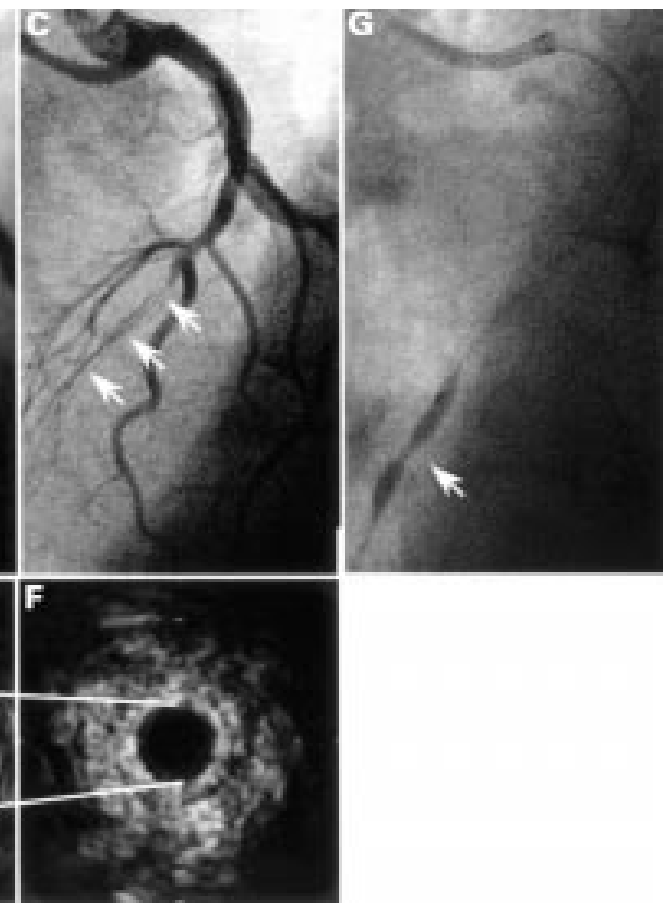

Figure 3 Corresponding angiographic and intravascular ultrasound images before $(A, D)$ and after $(B, E)$ stent implantation; stent collapse after seven weeks $(C, F)$ and unsuccessful re-PTCA with high pressure insufflation $(G)$. 
eration, or external compression (fig 2). One patient with total vessel occlusion after seven weeks showed severe recoil of the central and distal stent portion within the segment with the strongest systolic compression before implantation - minimum lumen diameter after stent implantation was $1.7 \mathrm{~mm}$, and after seven weeks it was $0.2 \mathrm{~mm}$ (fig 3, A-F). Even though it was feasible to advance the guidewire and intravascular ultrasound catheter through the occlusion site, a subsequent PTCA could not be performed successfully despite high balloon inflation pressures $(>20 \mathrm{~atm})$. This might have been because of external vessel resistance (fig $3 G)$. This patient underwent aortocoronary bypass surgery.

\section{Discussion}

Intracoronary stent implantation has been performed before in individual patients with myocardial bridges. ${ }^{16171922}$ In the present study, we assessed the long term outcome over a period of two years in a group of 11 patients with symptomatic myocardial bridges following intracoronary stent implantation.

The main findings were as follows. First, stent implantation in myocardial bridges is feasible and results in prompt relief of haemodynamic alterations. Second, at seven weeks, seven of a group of 11 patients were free of symptoms, though five showed in-stent stenosis of $\geqslant 50 \%$, as assessed by coronary angiography, and four of these had angina and underwent target vessel revascularisation - two underwent repeat transluminal balloon angioplasty, and two had bypass surgery (internal mammary artery bypass graft to the left anterior descending coronary artery); the remaining patient with in-stent stenosis was free of symptoms and was not treated. Third, at a two year follow up, all the patients-including those who had target vessel revascularisationwere free of symptoms without the need for further invasive diagnostic studies or antiischaemic treatment.

Intracoronary stents provide internal stabilisation of the vessel owing to the material stiffness which opposes the myocardial compression forces. Haemodynamic alterations caused by mural compression can be neutralised by intravascular stents. Thus for optimal stent deployment high insufflation pressures are mandatory, and should be under ultrasound control. Stents themselves, however, are associated with a risk of intimal proliferation with concomitant in-stent stenosis. In our small cohort of 11 patients with symptomatic myocardial bridges, five $(46 \%)$ developed in-stent stenosis of $\geqslant 50 \%$ of vessel diameter.

The fact that one of the first patients developed a complete collapse of the stent and consecutive occlusion of the left anterior descending coronary artery (without developing a transmural myocardial infarct) could be explained by suboptimal stent implantation, as in this single instance a relatively low inflation pressure was used (8 atm). However, four other patients $(36 \%)$ developed in-stent stenosis within seven weeks. The time interval of seven weeks was chosen to detect early mechanical recoil, which we considered likely to occur during the initial period following stent implantation. We were surprised to find that lumen diameters did not change significantly between seven weeks and six months of follow up. Other groups have looked at a time interval of three months ${ }^{35}$ and found no changes in luminal geometry thereafter. ${ }^{36} 37$ Our observations in our own small group with no evidence of coronary artery disease seem to imply that neointima formation appears to be a time related phenomenon following stent implantation.

It has been suggested that the main triggers of in-stent stenosis are either a local inflammatory response following balloon induced injury of the vessel wall or a recoil phenomenon which - at least in part - is not often seen with the newer generation of stents. ${ }^{38-40}$ It is not known, however, whether predictors and risk factors for in-stent stenosis or restenosis in patients with coronary artery disease are also important in patients with normal arterial wall composition. Moreover, the persistence of external compression within myocardial bridges might result in increased shear stress, potentially inducing a stimulus for intimal proliferation. Increased shear stress could be responsible for the development of atherosclerosis within myocardial bridges, which is normally a rare finding. ${ }^{41}$ If present, however, it might cause severe ischaemia. ${ }^{42}$ As we did not see any atherosclerosis within the bridged coronary segments on angiography or on intravascular ultrasound in our patients, pre-existing sclerotic plaques are unlikely to be the cause of in-stent stenosis.

Regarding the implantation data, the stented vessels were small in all our patients and they had long stented segments. Patients with in-stent restenosis had multiple stents, with a mean stent length of more than $25 \mathrm{~mm}$; the diameter of the reference segment in this subgroup was $2.0 \mathrm{~mm}$. These variables have been reported before as independent risk factors for restenosis-with increased risk ranging from $38 \%{ }^{43}$ up to $80 \%{ }^{44}$-and might also have played a role in our patient population.

\section{CONCLUSIONS}

Stent implantation may be an option for the treatment of selected patients with symptomatic myocardial bridging. If stenting is considered in this situation, we recommend the following:

- in our experience, highly flexible modified slotted tube or modular stents with good tractability are necessary; however, data comparing mechanical properties of different stent designs are sparse;

- high inflation pressures may be required for optimal stent implantation-intravascular ultrasound should be used as it provides unique information for verifying optimal stent expansion;

- the relative risk of in-stent stenosis caused by intimal proliferation must be considered, with the clinical need for reintervention. 
1 Angelini P, Trivellato M, Donis J, et al. Myocardial bridges: a review. Prog Cardiovasc Dis 1983;26:75-88.

2 Geiringer E. The mural coronary artery. Am Heart 71951 41:359.

3 Ross L, Dander B, Nidasio GP, et al. Myocardial bridges and ischemic heart disease. Eur Heart f 1980;1:239-45.

4 Bittl JA, Levin DC. Coronary arteriography. In: Braunwald $\mathrm{E}$, ed. Heart disease. A textbook of cardiovascular medicine. Philadelphia: WB Saunders, 1997:240-72.

5 Virmani R, Farb A, Burke AP. Ischemia from myocardial coronary bridging: fact or fancy? Hum Pathol 1993;24:6878.

6 McCabe MJ, Weston CF, Fraser AG. Acute myocardial infarction related to smoke inhalation and myocardial bridging. Postgrad Med $\mathcal{f}$ 1992;68:758-61.

7 Cottin Y, Laurent G, Gabrielle F, et al. Acute myocardial infarction related to myocardial bridging. Eur Heart $\mathcal{F}$ 1995;16:2002-3.

8 Chee TP, Jensen DP, Padnick MB, et al. Myocardial bridging of the left anterior descending coronary artery resulting ing of the left anterior descending coronary artery resulting in subendo

9 van Brussel BL, van Tellingen C, Ernst MP, et al. Myocardial bridging: a cause of myocardial infarction? Int $\mathcal{f}$ Cardiol 1984;6:78-82.

10 Tauth J. Myocardial infarction associated with myocardial bridging: case history and review of the literature. Cathet Cardiovasc Diagn 1997;40:364-7.

11 Desseigne P, Tabib A, Loire R. Myocardial bridging on the left anterior descending coronary artery and sudden death. Apropos of 19 cases with autopsy. Arch Mal Coeur Vaiss 1991;84:511-16. [In French.]

12 Nair CK, Dang B, Heintz MH, et al. Myocardial bridges: effect of propranolol on systolic compression. Can f Cardiol 1986;2:218-21.

13 Schwarz ER, Klues HG, vom Dahl. Functional, angiographic and intracoronary Doppler flow characteristics in symptomatic patients with myocardial bridging: effect of symptomatic patients with myocardial bridging: effect of
short-term intravenous beta-blocker medication. $7 \mathrm{Am} \mathrm{Coll}$ short-term intravenous beta-
Cardiol 1996;27:1637-45.

14 Katznelson Y. Myocardial bridging: surgical technique and operative results. Mil Med 1996;161:248-50.

15 Prasad VS. Modified supra-arterial myotomy for intermittent coronary obstruction by myocardial bridges. Scand $\mathcal{F}$ Thorac Cardiovasc Surg 1995;29:91-3.

16 Stables RH, Knight CJ, McNeill JG, et al. Coronary stenting in the management of myocardial ischaemia caused by muscle bridging. Br Heart $\mathcal{F} 1995 ; 74: 90-2$.

17 Smith SC, Taber MT, Robiolio PA, et al. Acute myocardial infarction caused by a myocardial bridge treated with intra-
coronary stenting. Cathet Cardiovasc Diagn 1997;42:20912.

18 Jeremias A, Haude M, Ge J, et al. Bail-out stent implantation of a muscle bridging in the left anterior descending artery after post-interventional dissection. Z Kardiol 1997;86: after post-i.

19 Hering D, Horstkotte D, Schwimmbeck P, et al. Acute myocardial infarct caused by a muscle bridge of the anterior interventricular ramus: complicated course with vascular interventricular ramus: complicated course with vascular perforation $630-8$.

20 Rzezniczak J, Angerer D, Kalawski R, et al. Intracoronary stent implantation for treatment of myocardial ischemia induced by myocardial bridge. A case report. Kardiol Pol 1998; 48:521

21 Klues HG, Schwarz ER, vom Dahl. Disturbed intracoronary hemodynamics in myocardial bridging: early normalization by intracoronary stent placement. Circulation 1997;96:2905-13

22 Bayes A. Coronary stenting for symptomatic myocardial bridging. Heart 1998;80:102-3.

23 Marti V, Ramirez J, Lamich R, et al. Coronary stent placement for recurrent angina secondary to myocardial bridging. Rev Med Chil 1998;126:1362-6.
24 Haager PK, Klues HG, Schmidt M, et al. Effect of nitroglycerin and nicorandil on regional poststenotic quannitroglycerin and nicorandil on regional poststenotic quancombined digital quantitative angiographic and intracoro-
comberon nary Doppler study. I Cardiovasc Pharmacol 1999;33:12634.

25 Kern MJ. Intramyocardial bridge coronary flow velocity in a diseased coronary artery. Cathet Cardiovasc Diagn 1995;35: 131.

26 Doucette JW, Corl PD, Payne HM, et al. Validation of a Doppler guide wire for intravascular measurement of coronary artery flow velocity. Circulation 1992;85:1899911.

27 Ofili EO, Labovitz AJ, Kern MJ. Coronary flow velocity dynamics in normal and diseased arteries. Am 7 Cardiol 1993;71:3-9D.

28 Wilson RF, White CW. Intracoronary papaverine: an ideal coronary vasodilator for studies of the coronary circulation in conscious humans. Circulation 1986;73:444-51.

29 Dyet JF, Watts WG, Ettles DF, et al. Mechanical properties of metallic stents: how do these properties influence the choice of stent for specific lesions? Cardiovasc Intervent Radiol 2000;23:47-54.

30 Rieu R, Barragan P, Masson C, et al. Radial force of coronary stents: a comparative analysis. Cathet Cardiovasc Intervent 1999;46:380-91.

31 Colombo A, Hall P, Nakamura S, et al. Intracoronary stenting without anticoagulation accomplished with intravascular ultrasound guidance. Circulation 1991;91:1676-88.

32 Diefenbach C. Incidence of myocardial bridges after adrenergic stimulation and decreasing afterload in patients with angina pectoris, but normal coronary arteries. $Z$ Kardiol 1994;83:809-15.

33 Schomig A, Neumann FJ, Kastrati A, et al. A randomized comparison of antiplatelet and anticoagulant therapy after the placement of coronary-artery stents. N Engl f Med 1996;334:1084-9

34 Ge J, Erbel R, Rupprecht HJ, et al. Comparison of intravascular ultrasound and angiography in the assessment of myocardial bridging. Circulation 1994;89:1725-32.

35 Asakura M, Ueda Y, Nanto S, et al. Remodeling of in-stent neointima, which became thinner and transparent over 3 years: serial angiographic and angioscopic follow-up. Circulation 1998;97:2003-6.

36 Kastrati A, Schomig A, Dietz R, et al. Time course of restenosis during the first year after emergency coronary

37 Kimura T, Nosaka H, Yokoi H, et al. Serial angiographic follow-up after Palmaz-Schatz stent implantation: comparion with conventional balloon angioplasty. $\mathcal{F} \mathrm{Am}$ Coll Cardiol 1993;21:1557-63.

38 Edelman ER, Rogers C. Hoop dreams: stents without restenosis. Circulation 1996;94:1199-202.

39 Edelman ER, Rogers C. Pathobiologic responses to stenting. Am f Cardiol 1998;81:4-6E.

40 Rogers C, Edelman ER. Endovascular stent design dictates experimental restenosis and thrombosis. Circulation 1995; 91:2995-3001.

41 Ge J, Erbel R, Gorge G, et al. High wall shear stress proximal to myocardial bridging and atherosclerosis: intracoronary ultrasound and pressure measurements. Br Heart $\mathcal{f}$ 1995;73:462-5.

42 de Winter RJ, Kok WE, Piek JJ. Coronary atherosclerosis within a myocardial bridge, not a benign condition. Heart 1998;80:91-3

43 Elezi S, Kastrati A, Neumann FJ, et al. Vessel size and longerm outcome after coronary stent placement. Circulation 1998;98:1875-80

44 Lansky J, Stone GW, Mehran R et al. Impact of vessel size and lesion length on outcomes after primary stenting versus primary angioplasty in acute myocardial infarction: results from stent PAMI [abstract]. Eur Heart f 1999;20: 615. 